\title{
SATELLITE-BASED MODELING OF ANOPHELES MOSQUITO DENSITIES ON HETEROGENEOUS LAND COVER IN WESTERN THAILAND
}

\author{
A. Charoenpanyanet ${ }^{\mathrm{a}}$ and X. Chen ${ }^{\mathrm{a}}$ \\ ${ }^{\text {a }}$ Remote sensing and Geographic Information Systems Field of Study, School of Engineering and Technology,Asian \\ Institute of Technology, Thailand, arisara_cmu@hotmail.com, xychen@ait.ac.th
}

KEY WORDS: Remote Sensing, Land Cover, Statistics, Modeling, Landsat, Satellite

\begin{abstract}
:
Landsat 5 TM was used as a tool to model Anopheles mosquito densities on heterogeneous land cover. In this study, mosquito density data was divided into 5 classes; absence, low, moderate, high, and very high densities. Land cover was classified into 8 types. Stagnant water, wetland, and paddy land cover types are larva habitat. Forest, cropland, orchard, and grassland land cover types are adult habitat. Built-up land is non habitat. Multiple linear regression and discriminant analysis were selected to identify the relationship between mosquito densities and land cover types. For the average flight range of mosquitoes, 1000, 2000, and 3000 meters buffer were used as the sample zones around the collected points to test the relationship between them. The results revealed that discriminant analysis is the best statistical model for fitting the model. The mosquito flight range of 1000, 2000, and 3000 meters were predicted with accuracies up to $80 \%$, followed by $74.3 \%$, and $54.3 \%$, respectively. Relationships between mosquito density and heterogeneous land cover in this study appear to be varied upon forest, grassland, and larva habitat within the 1000 meters buffer, likewise, forest, and larva habitat within 2000 meters buffer.
\end{abstract}

\section{INTRODUCTION}

Malaria is one of the high priority tropical diseases in Thailand. Although, there have been many efforts to eradicate malaria from the world over a long period of time, yet it remains a complex disease. It affects human health and continues to be one of the most serious vector-borne diseases world-wide. Malaria transmits through 3 possible mediums; malaria parasite, human hosts, and Anopheles mosquito. The way to solve the malaria problem is to intervene these mediums. This study focused on Anopheles mosquito, a part of the malaria transmission cycle. The suitable environmental conditions for various behaviors of Anopheles mosquito such as resting, swarming, oviposition, biting, and feeding are examined. The characteristic of heterogeneous space is an important factor to predict the mosquito densities. The heterogeneous space is called "land cover".

Heterogeneous land cover encourages vector-borne disease transmission in several ways. Recent studies found that mosquito density correlated with forest mean patch size and fruit orchard fractal dimension (Overgaad et al., 2001). Furthermore, the landscape features correlated with the density of An. Albimanus and malaria incidence (Beck et al., 1994; Rejmankova et al., 1995; Snow et al., 1998). Some studies show the relationship between land use and mosquito density, for instance dam creation and urbanization have increased mosquito productivity (Patz et al., 2000; Norris, 2004).

Malaria has been studied using remotely sensed data. NOAA and METEOSAT, weather monitoring satellite, are the most effective in predicting changes in malaria transmission dynamics. Thomson et al. (1997) found the positive relationship between rainfall and NDVI value and vector abundance. Nualchawee et al. (1997) and Montgometry et al. (1998) used Landsat to study the relationship between the incidence of malaria transmission and vegetation covers. Some studies show that land cover classes affect malaria transmission. Moreover, satellite imagery was applied to extract the parameters and found the association with the mosquitoes. Also, Barnes and Cibula (1979), Later Hayes et al. (1985) and Thomas and Lindsay (2000) used Landsat 1, 2 and SPOT to classify vegetation cover, fresh water plants, and land cover types. The result revealed that these parameters associated with the breeding habitat. Land cover and NDVI values are significantly correlated with density of mosquitoes (Pope et al., 1994 and Thomson et al., 1997). The immature collections of Anopheles mosquitoes are significantly correlated with land use as determined in the land use classification (Sithiprasasna et al., 2005). Mosquito larval habitats are associated with wetland areas and aquatic vegetation (Kaya et al., 2004 and Vasconcelos and Novo, 2003). Cross et al. (1984) used Landsat MSS data to describe the geographic (landscape) characteristics of sites in the Philippine Islands where cases of schistosoiasis were reported. These measurements were combined with temperature and precipitation data to estimate the probability of disease occurrence at specific locations. Beside, NOAA AVHRR data is used to infer ecological parameters associated with Rift Valley Fever (RVF) in Kenya. Correlations between vegetation index values and ecological parameters indicated the possibility of predicting RVF viral activity in the mosquito vector (Linthicum et al., 1987). This work was extended by Pope et al. (1992) who used Landsat TM to identify potential vector breeding sites known as dambos.

In other words, mathematical models provide a sound understanding risks and planning for control in heterogeneous environments, especially when the models are based on the ecology of the local vector populations and a sound understanding of the entomological parameters relevant for transmission (Killeen et al., 2000). They can bridge the gaps between landscape ecology, vector biology, and human epidemiology, linking large-scale maps to individual risk in local human populations at spatial scales ranging from $10 \mathrm{~m}$ up to $10 \mathrm{~km}$ (Bidlingmyer, 1985).

Fewer studies have examined the prediction mosquito density on heterogeneous land cover. The focus of this study was 
therefore to create model for predicting Anopheles mosquito densities which based on satellite imagery into classify heterogeneous land cover. Remote sensing technology was used to answer the questions by linking between the Anopheles mosquito densities, mosquito habitat, mosquito life cycle, and heterogeneous land cover. A spatial density pattern of mosquito was determined, then analyzed to obtain the correlation with land cover types. Also, the relationship between land cover and habitats of Anopheles mosquito was determined. The best fitted model was derived from statistical models. Knowledge of the effects of land cover types and topography on mosquito habitat distribution is useful for predicting the density of Anopheles mosquito and the impacts of different land cover types practice on malaria transmission, and thus for designing novel strategies for malaria intervention.

\section{STUDY AREA}

The number of malaria reported cases in Thailand show a decreasing trend during past two decades, and even disappearing from most of the major cities (Ministry of Public Health, 2003). However, people in rural areas, especially in villages along the Thailand-Myanmar and Thailand-Cambodia borders and forested mountain areas, remain at great risk (Somboon et al., 1998). In these endemic areas, malaria transmission has been considered to have a close association with the forest and movement of the human population (Ministry of Public Health, 2003). However, little is known about spatial patterns and dynamics of malaria in Thailand.

This study was conducted in some areas of Sai Yok district in the western part of Kanchanaburi province, Thailand (latitude $14^{\circ} 15^{\prime} \mathrm{N}$ and longitude $99^{\circ} 20^{\prime} \mathrm{E}$ ) (Figure 1).

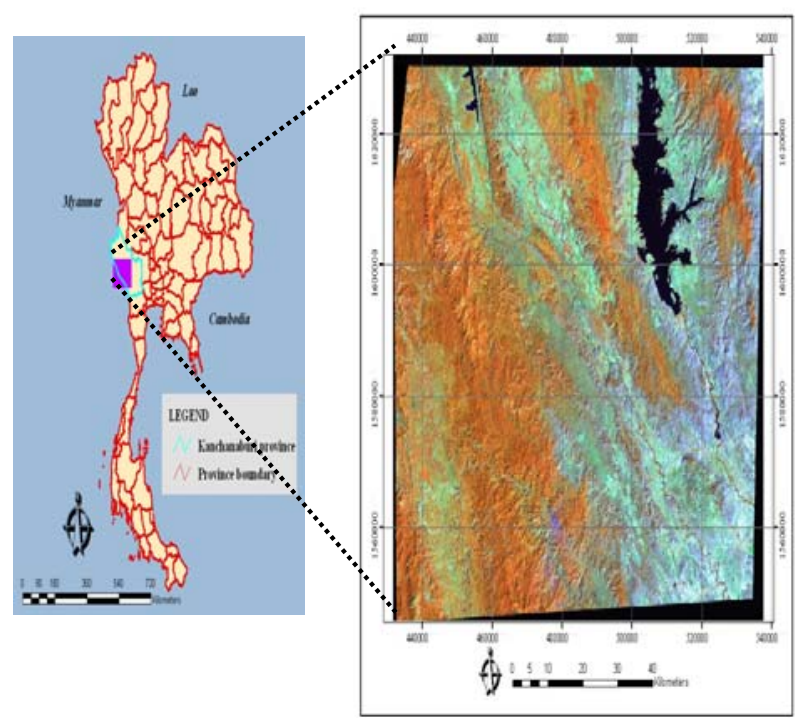

Figure 1. Study area in some areas of Sai Yok district, Kanchanaburi province, Thailand

\section{METHODOLOGY}

\subsection{Mosquito data}

Mosquito data was obtained from Vector Borne Disease Control Center 4.1 Kanchanaburi. There are 4 species of Anopheles mosquitoes found in Sai Yok district, the study area. They are as follows:

- Primary vector

- Anopheles minimus

- An. dirus

- An. maculatus

- $\quad$ Secondary vector

- An. aconitus

Although, these species have their feeding behaviors both outdoor and indoor environment, this study however only focused on outdoor behavior, as it would not be possible to apply satellite imagery to extract the parameters for indoor. Four Anopheles mosquito species were grouped together in the map.

While larva and pupa densities do not necessarily correlate with adult emergence success, they are commonly used as a surrogate for adult productivity in surveillance and control surveys, and ecological studies (WHO, 1982). Hence, this study used only the density of adult mosquito. The density of the adult mosquitoes was collected in the malaria transmission area, about 31 sub-villages and in the free malaria area about 4 subvillages. Sampling was performed through outdoor biting and resting collections. The collection was carried-out in wet season (July-August). Average density of Anopheles mosquito was estimated by the averaging number of female mosquito bits per collector per hour. The mosquito densities were divided into 5 classes; they are absence, low density, moderate density, high density, and very high density, depending up on with the ranges of $0,1-5,6-11,12-19$, and 20-45 females bite/person/hour, respectively (Table 1 ).

\subsection{Buffering}

A buffer is a polygon that encloses all areas within a set distance of the spatial features. In this study, buffer zones were created around every point that represents adult mosquito sources in the mosquito density map. These buffer zones were divided into 3 groups according to the average distance that Anopheles mosquito would travel per day. Therefore, the buffer zones of 1000 meters, 2000 meters, and 3000 meters around every Anopheles mosquito collected points (mosquito density) were created by using GIS.

\subsection{Satellite imagery}

The land cover types were classified by using Landsat5 TM. $\mathrm{TM}$ is one of the most applicable satellites for environmental studies. TM has seven bands; six of them are in the visible and near infrared wavelength and one of them is in the thermal infrared wavelength. Satellite imagery was required to cover the Sai Yok district, with path: 130 and row: 50, in wet season (August) in 2005. 


\begin{tabular}{|c|c|c|c|}
\hline Sub-village & Tambon & Category & $\begin{array}{c}\text { Mosquito } \\
\text { density }\end{array}$ \\
\hline Wang Sing & Sing & Absence & 0 \\
\hline Nong Pralai & Sing & Absence & 0 \\
\hline Yang Ton & Sri Mongkol & Absence & 0 \\
\hline Nong Prue & Sing & Absence & 0 \\
\hline Lawa Cave & Wang Krajae & Low & 0.56 \\
\hline Pak Lum & Wang Krajae & Low & 0.67 \\
\hline Pu Namron & Lum Sum & Low & 1 \\
\hline Mu Supan & Lum Sum & Low & 2 \\
\hline Nong Hoi & Sri Mongkol & Low & 2.12 \\
\hline Samukkee Thum & Lum Sum & Low & 2.43 \\
\hline Kata Thong & Sri Mongkol & Low & 3 \\
\hline Huai Kawlam & Bong Ty & Low & 3.09 \\
\hline Kaeng Pralom & Sai Yok & Low & 3.33 \\
\hline Mae Nam Noi & Sai Yok & Low & 5 \\
\hline Pu Rungroeng & Sri Mongkol & Moderate & 5.33 \\
\hline Hat Ngiu & Wang Krajae & Moderate & 5.66 \\
\hline Huai Manow & Bong Ty & Moderate & 6 \\
\hline Dong Pong & Wang Krajae & Moderate & 6 \\
\hline Rai Zak & Wang Krajae & Moderate & 6.78 \\
\hline Nong Pladook & Sri Mongkol & Moderate & 7.32 \\
\hline Ton Mamuang & Wang Krajae & Moderate & 9.08 \\
\hline Thung Ma Soe Yo & Bong Ty & Moderate & 9.43 \\
\hline Chy Thung & Wang Krajae & Moderate & 9.59 \\
\hline Sri Mongkol & Sri Mongkol & Moderate & 11 \\
\hline Bong Ty Noi & Wang Krajae & Moderate & 11 \\
\hline Khao Yai & Bong Ty & Moderate & 11.32 \\
\hline Hin Kong & Bong Ty & High & 12 \\
\hline Phu Toei & Bong Ty & High & 12 \\
\hline Prado Thong & Bong Ty & High & 12.2 \\
\hline Ton Tal & Bong Ty & High & 13 \\
\hline Kho Kae & Wang Krajae & High & 15 \\
\hline Bong Ty Bon & Bong Ty & Very high & 35 \\
\hline Pang Mai & Bong Ty & Very high & 35 \\
\hline Bong Ty Lang & Bong Ty & Very high & 42.12 \\
\hline Thai Mueang & Bong Ty & Very high & 45.29 \\
\hline
\end{tabular}

Table 1. Anopheles mosquito density classes in the study area

\subsection{Land cover classification}

Supervised classification method was used to classify the land cover types. This was done by defining regions of interests (ROIs) that represent each of the land cover types. Utmost attention was made in selecting ROIs that are homogeneous by exporting them to n-D Visualizer function of ENVI 4.X image processing software and correcting for overlaps between classes. After the ROIs are finalized, maximum likelihood classification was performed to assign each pixel in the subset image data to the class that has the highest probability.

There are 8 land cover types in this study area. They are stagnant water, wetland, paddy, forest, orchard, cropland, grassland, and built-up land. Each type relates to the mosquito life cycle. Creating of the mosquito density map requires mapping of larva and adult habitat. These maps were combined with a real mosquito density from filed surveying. Eggs, larva, and pupa habitat are called larva habitat. These were extracted from only stagnant/standing water such as reservoir, pond, well, wetland and paddy. While the adult habitat appears in 4 land cover types; forest, grassland, orchard, and cropland. The builtup land was defined as mosquito non-habitation area (Figure 2).

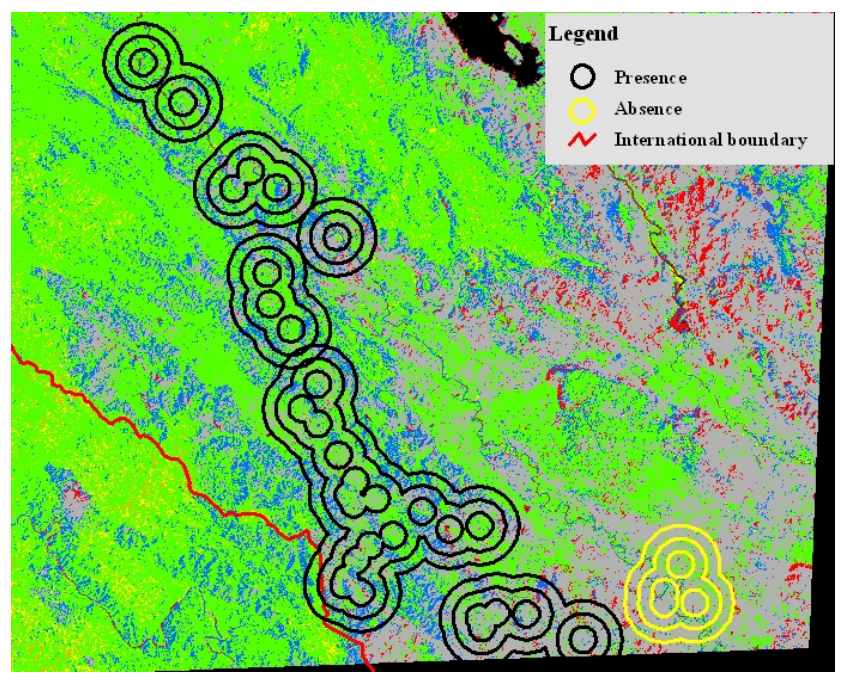

Figure 2. Buffer zones of 1000, 2000, and 3000 meters related to land cover types

\subsection{Statistical model}

Two statistical models, multiple linear regression and discriminant analysis, were applied to create the model. Multiple linear regression was applied to create the model to illustrate relationship between Anopheles mosquito density zones (1000 meters, 2000 meters, and 3000 meters buffer) and land cover types. The multiple regression equation takes the form as follows.

$\mathrm{Y}=\mathrm{b}_{1} \mathrm{x}_{1}+\mathrm{b}_{2} \mathrm{x}_{2}+\ldots+\mathrm{b}_{\mathrm{n}} \mathrm{x}_{\mathrm{n}}+\mathrm{c}$

where the b's are regression coefficients, the x's are the score of the variables or predictors and $\mathrm{c}$ is a constant.

Discriminant analysis, stepwise method, was also applied to create the model. The model is built based on a set of observations for which the classes are known. This set of observations is sometimes referred to as the training set. Based on the training set, the technique constructs a set of linear functions of the predictors, known as discriminant functions, such that

$\mathrm{Y}=\mathrm{b}_{1} \mathrm{x}_{1}+\mathrm{b}_{2} \mathrm{x}_{2}+\ldots+\mathrm{b}_{\mathrm{n}} \mathrm{x}_{\mathrm{n}}+\mathrm{c}$

where the b's are discriminant coefficients, the x's are the input variables or predictors and $\mathrm{c}$ is a constant. It was used to determine which variables discriminant between five naturally occurring groups.

\section{RESULTS AND DISCUSSION}

Discriminant analysis was found to be the best statistical model for fitting the model to predict the Anopheles mosquito densities 
on heterogeneous land cover. Three models were created (Table 2). However, the models that were able to predict the mosquito density correctly more than $70 \%$ are model 1 (=1000 meters) and model 2 (=2000 meters), with the accuracy $80 \%$ and $74.3 \%$, respectively. In comparison, model 3 (=3000 meters) was able to predict correctly only $54.3 \%$. Similar method was used by Beck et al. (1994) could identify high risk, low risk and nonmalarious villages with $90 \%$ accuracy buffer of $1 \mathrm{~km}$ around villages. Condition Autoregressive (CAR) model is the best fitted model for mosquito density prediction in the indoor environment. Then, a climate-based statistical model of transmission intensity was developed (Snow et al., 1998). This model correctly identified $75 \%$ of three endemic classes. The model was applied to meteorological and remotely sensed data using GIS to provide estimates of endemic. Rainfall and temperature data were derived from weather station reports, whereas NDVI was extracted from NOAA-AVHRR satellite sensor. These data were resampled according to the location of the parasitological surveys (Smith et al., 1995).

Independent variables of the model 1 were forest 1000 , grassland1000, and larva habitat1000 land cover types within 1000 meters buffer to predict mosquito density. For model 2, then, forest2000 and larva habitat2000 were identified as the independent variables within 2000 meters buffer to predict mosquito density (see also in Figure 2). The result shows that each type of land covers influence differently to the mosquito density. This also supports to the previous finding that land use influences the density of immature mosquitoes in larva habitat (Gratz, 1999; Patz et al., 2000). This study reveals a significant relationship between heterogeneous land cover and mosquito densities. Among 1000 meters, 2000 meters, and 3000 meters buffer, the forest land cover type has the highest correlation with mosquito densities, followed by grassland land cover type and larva habitat land cover types (stagnant water, wetland, and paddy). In other word, forest would have more distribution and density of mosquito. The previous work, similarly, has shown that Anopheles mosquito correlated positive with forest mean patch size (Overgaard et al., 2001).

Also, the results of this study are similar with other previous studies. Those studies used three ranges of average travel distance, they are 0-500, 501-1500 and $>1500$ meters. The adult mosquito density in houses that are near to the larva habitats were recorded as landing rate of 0.5 mosquitoes per human per minute. Predictions of mosquito densities have an accuracy up to $89 \%$ for high density sites, while $100 \%$ for the sites more than 1500 meters away, was low (Rejmankova et al., 1995). In another study, a step-wise discriminant analysis, using Landsat TM channels, was performed to predict high and low mosquitoproducing fields. The results of the analysis were correctly identified of $75 \%$ of the high, and $80 \%$ of the low producing fields (Wood et al., 1992).

For model 1:

Absence $=-13.582+3.202$ (forest1000) +5.502 (grassland1000) + 3.944 (larva habitat1000)

Low $=-34.836-9.893($ forest1000 $)+12.726($ grassland 1000$)+$ 6.779 (larva habitat1000)
Moderate $=-36.973+0.802$ (forest1000) +13.07 (grassland1000) +5.829 (larva habitat1000)

High $=-53.738+28.729($ forest1000) +10.167 (grassland1000) +5.273 (larva habitat1000)

Very high $=-71.217+45.237$ (forest1000) +8.992 (grassland1000) +4.13 (larva habitat1000)

The results of each density class for model 1 was able to identify correctly $100 \%$ of the absence, $80 \%$ of the low, $66.7 \%$ of the moderate, $100 \%$ of the high, and $75 \%$ of the very high density.

\begin{tabular}{|c|c|c|c|c|c|}
\hline \multirow[t]{2}{*}{$\begin{array}{l}\text { Independent } \\
\text { Variable }\end{array}$} & \multicolumn{5}{|c|}{ Mosquito density classes (Dependent Variable) } \\
\hline & Absence & Low & Moderate & High & $\begin{array}{l}\text { Very } \\
\text { high }\end{array}$ \\
\hline \multicolumn{6}{|l|}{$\begin{array}{l}\text { Model } 1 \\
(=1000 \mathrm{~m})\end{array}$} \\
\hline Forest1000 & 3.202 & -9.893 & 0.802 & 28.729 & 45.237 \\
\hline $\begin{array}{l}\text { Grassland10 } \\
00 \\
\text { Larva }\end{array}$ & 5.502 & 12.726 & 13.07 & 10.167 & 8.992 \\
\hline Constant & -13.582 & -34.836 & -36.973 & -53.738 & -71.217 \\
\hline \begin{tabular}{l}
\multicolumn{2}{c}{ Function1 } \\
at group \\
centriods \\
Function2
\end{tabular} & -1.974 & -2.708 & -0.562 & 3.426 & 6.146 \\
\hline $\begin{array}{l}\text { at group } \\
\text { centriods }\end{array}$ & -3.252 & 0.438 & 0.836 & -0.034 & -0.309 \\
\hline \multicolumn{6}{|l|}{$\begin{array}{l}\text { Model } 2 \\
(=2000 \mathrm{~m})\end{array}$} \\
\hline $\begin{array}{l}\text { Forest2000 } \\
\text { Larva }\end{array}$ & 22.507 & 10.71 & 19.488 & 29.306 & 48.97 \\
\hline habitat2000 & 31.167 & 41.74 & 55.538 & 66.006 & 75.757 \\
\hline Constant & -13.198 & -14.749 & -26.642 & -40.12 & -64.455 \\
\hline $\begin{array}{l}\text { at group } \\
\text { centriods } \\
\text { Function2 }\end{array}$ & -1.777 & -2.014 & -0.003 & 1.826 & 4.538 \\
\hline $\begin{array}{l}\text { at group } \\
\text { centriods }\end{array}$ & 1.755 & -0.197 & -0.478 & -0.396 & 0.667 \\
\hline $\begin{array}{l}\text { Model } 3 \\
(=3000 \mathrm{~m})\end{array}$ & & & & & \\
\hline Forest3000 & 4.538 & 6.754 & 7.413 & 9.12 & 10.576 \\
\hline Constant & -10.539 & -21.391 & -25.435 & -37.669 & -50.105 \\
\hline
\end{tabular}

Table 2. Results from the discriminant analysis model

For model 2:

Absence $=-13.198+22.507$ (forest2000) +31.167 (larva habitat2000)

Low $=-14.749+10.710$ (forest2000) +41.74 (larva habitat2000) 
Moderate $=-26.642+19.488$ (forest2000) +55.538 (larva habitat2000)

High $=-40.12+29.306$ (forest2000) +66.006 (larva habitat2000)

Very high $=-64.455+48.97$ (forest2000) +75.757 (larva habitat2000)

Otherwise, the results of each density class for model 2 was able to identify correctly $75 \%$ of the absence, $80 \%$ of the low, $75 \%$ of the moderate, $60 \%$ of the high, and $75 \%$ of the very high density.

\section{CONCLUSION}

This study addresses spatial patterns of Anopheles mosquito densities through the use of remotely sensed data. It focused on the relationship of mosquito life cycle, heterogeneous land cover and mosquito densities and habitats, to create the mosquito density prediction model. The model accuracy of mosquito densities was negatively correlated with buffer zone distance from Anopheles mosquito collected points. The result commonly confirms that the closer distance to the mosquito collected points, the better prediction accuracy of the mosquito density it gets. The previous studies found that the mosquito average flight range is approximately 1000-3000 meters, depending on the environmental condition and time, such as wind direction, wind current, physical barrier, hill, tree, distance from breeding source and human habitat, etc.

The result of this study is a useful tool to help in forecasting of malaria transmission by knowing where land cover types would appear the malaria vector or where the suitable habitats of malaria vector would be. The result could also be applied to vector control measure by environmental management method for man-mosquito contact reduction. This measure was proved from many countries that can reduce the vector density and breeding sources.

\section{REFERENCES}

Barnes, C., and Cibula, W., 1979. Some implications of remote sensing technology in insect control programs including mosquitoes. Mosq. News 39: pp. 271-282.

Beck, L.R., Rodríguez, M.H., Dister, S.W., Rodríguez, A.D., Rejmankova, E., Ulloa, A., Meza, R.A., Roberts, D.R., Paris, J.F., Spanner, M.A., Washino, R.K., Hacker, C., and Legters, L.J., 1994. Remote sensing as a landscape epidemiological tool to identify villages at high risk for malaria transmission. Am. J. Trop. Med. Hyg. 51(3): pp. 271-280.

Bidlingmyer, W.L., 1985. The measurement of adult mosquito population change-Some considerations. J. Am. Mosq. Control Assoc. 1: pp. 328-348.

Gratz, N.G., 1999. Emerging and resurging vector-borne diseases. Annual Review of Entomology 44: pp. 51-75.

Kaya, S., Sokol, J., and Pultz, T.J., 2004. Monitoring environmental indicators of vector-borne disease from space: a new opportunity for RADARSAT-2. Can. J. Remote Sensing 30(3): pp. 560-565.

Killeen, G.F., McKenzie, F.E., Foy, B.D., Schieffelin, C., Billingsley, P.F and et al., 2000a. A simplified model for predicting malaria entomologic inoculation rates based on entomologic and parasitologic patterns relevant to control. Am. J. Trop. Med. Hyg. 62: pp. 535-544.

Killeen, G.F., McKenzie, F.E., Foy, B.D., Schieffelin, C., Billingsley, P.F and et al., 2000b. The potential impact of integrated malaria transmission control on entomologic inoculation rate in highly endemic areas. Am. J. Trop. Med. Hyg. 62: 545-551.

Norris, D.E., 2004. Mosquito-borne diseases as a consequence of land use change. Ecohealth 1: pp. 19-24; DOI: 10.1007/s10393-004-0008-7.

Overgaard, H.J., Ekbom, B., Suwonkerd, W., Takagi, M., 2003. Effect of landscape structure on anopheline mosquito density and diversity in northern Thailand: Implications for malaria transmission and control. Landscape Ecology 18: pp. 605-619.

Patz, J.A., Graczyk, T.K., Geller, N., Vittor, A.Y., 2000. Effects of environmental change on emerging parasitic disease. International Journal for Parasitology 30: pp. 1395-1405.

Pope, K.O., Rejmankova, E., Savage, H.M., Arredondo-Jimenez, J.T., Rodriguez, M.H., and Robert, D.R., 1994. Remote sensing of tropical wetlands for malaria control in Chiapas, Mexico. Ecological Application 4(1): pp. 81-90.

Rejmankova, E., Roberts, D.R., Pawley, A., Manguin, S. and Polanco, J., 1995. Predictions of adult Anopheles albimanus densities in villages based on distance to remotely sensed larval habitats. Am. J. Trop. Med. Hyg. 53: p. 482.

Sithiprasasna, R., Lee, W.J., Ugsang, D.M., and Linthicum, K.J., 2005. Identification and characterization of larval and adult anopheline mosquito habitats in the Pepublic of Korea: potential use of remotely sensed data to estimate mosquito distributions. International Journal of Health Geographics 4: p. 17.

Smith, T., Charlwood, J.D., Takken, W., Tanner, M., and Spiegelhalter, D.J., 1995. Mapping the densities of malaria vectors within a single village. Acta Tropica 59: pp. 1-18.

Snow, R.W., Gouws, E., Omumbo, J., Rapuoda, B., Craig, M.H., Tanser, F.C., Sueur,D., and Ouma, J., 1998. Models to predict the intensity of Plasmodium falciparum transmission: applications to the burden of disease in Kenya. Tropical Medicine and Hygiene 92: pp. 601-606.

Somboon, P., and et al., 1998. Entomological and epidemiological investigations of malaria transmission in relation to population movement in forest areas of north-west Thailand. Southeast Asia J. Trop. Med. Public Health 29: pp. 39.

Thomas, C.J., and Lindsay, S.W., 2000. Local-scale variation in malaria infection amongst rural Gambian children estimated by satellite remote sensing. Tropical Medicine and Hygiene 94: pp. 159-163. 
Thomson, M.C., Connor, S.J., Milligan, P., and Flasse, S.P., 1997. Mapping Malaria Risk in Africa: What can Satellite Data Contribute?. Parasitology Today 13(8): pp. 313-318.

Vasconcelos, C.H., and Novo, E., 2003. Influence of precipitation, deforestation and Tucurui reservoir operation on malaria incidence rates in Southeast Para, Brazil. IEEE: pp. 4567-4569.

WHO, 1982. Mosquito, mosquito-borne disease and mosquito control methods: a review. In: Manual on Environmental Management for mosquito Control with Special Emphasis on Malaria Vectors, Geneva: World Health Organization, pp. 11-22.
Wood, B.L., Beck, L.R., Washino, R.K., Hibbard, K.A. and Salute, J.S., 1992. Estimating high mosquito producing rice fields using spectral and spatial data. Int. J. Remote Sensing 13: pp. 2813.

\section{ACKNOWLEDGMENTS}

Special thanks to the mosquito collection team and staff of the Office of Vector Borne Disease Control Center 4.1 in Kanchanaburi for their assistance in general support. The authors would like to also thank Dr.Taravudh Tipdacho for kind help in various ways during the course of this study. 